The Psychological Record, 2010, 60, 473-488

\title{
ESTABLISHING MAND EMERGENCE: THE EFFECTS OF THREE TRAINING PROCEDURES AND MODIFIED ANTECEDENT CONDITIONS
}

\author{
Claire E. Egan and Dermot Barnes-Holmes \\ National University of Ireland, Maynooth
}

\begin{abstract}
This study examined the effects of a modified antecedent during probes for emergent mands following listener versus tact training for children with autism. Eight students, aged 7 to 11, were trained to respond to 3 sets of relational responses (front/back, left/right, on/under), each assigned a nonsense label. Three training types were evaluated: listener training, tact training, and listener-tact training combined. Following the experimental training, probes for emergent mands were conducted under modified antecedent conditions. Results showed that modified antecedent conditions were critical in demonstrating mand emergence for some participants.
\end{abstract}

Key words: autism, expressive language, mand, receptive language, tact

Skinner's (1957) theory of verbal behavior categorized several classes of verbal operants according to the antecedent and consequential controlling variables unique to each operant. Since that time, two of these verbal operants, the mand and the tact, have been examined closely in the behavioral research literature.

Skinner (1957) defined mand as a verbal response evoked by conditions of deprivation or aversive stimulation in which the response is followed by a characteristic consequence. Michael (1982) referred to these preceding conditions as establishing operations (EO) and further refined the concept to include any environmental changes that alter the value of the consequence in mand operants. Mands have been distinguished from other verbal operants based on (a) the presence of EOs as a primary controlling variable and (b) the characteristic consequence following the response. Tacts were defined as verbal responses evoked by nonverbal discriminative stimuli followed by generalized reinforcement (Skinner, 1957).

According to Skinner (1957), the controlling variables defining each of these verbal operants made them functionally independent. Therefore,

Claire E. Egan and Dermot Barnes-Holmes, Department of Psychology, National University of Ireland, Maynooth.

Claire E. Egan is now at the Hong Kong Institute for Education. Correspondence concerning the study should be addressed to Claire E. Egan, The Hong Kong Institute for Education, Department of Special Education and Counselling, 10 Lo Ping Road, Tai Po, New Territories, Hong Kong-SAR (e-mail: claire@ied.edu.hk).

These experiments were completed as part of the doctoral work submitted by Claire E. Egan to the Department of Psychology at NUI, Maynooth. 
a response form could be categorized as a mand or a tact, depending on the antecedent and consequent variables present in a given context. Furthermore, a response form acquired as a mand/tact might not emerge as a tact/mand without direct reinforcement.

The issue of functional independence and mand/tact emergence has become an important topic in current behavioral research literature. The goal of much of this research has been to establish effective communicationtraining programs for persons with developmental disabilities (Sundberg \& Partington, 1998). Researchers in this area have often focused on establishing "emergent" verbal behavior in which a response acquired under the controlling conditions of one verbal operant transfers to the conditions of another without direct instruction (Hernandez, Hanley, Ingvarsson, \& Tiger, 2007; Nuzzolo-Gomez \& Greer, 2004; Rosales \& Rehfeldt, 2007). It has been observed that children with autism spectrum disorders (ASD) lack this type of emergent responding. By better understanding how functional independence is defined and the conditions under which it can be observed, researchers and educators can work to develop interventions that overcome functional independence and establish emergent or generative language.

Previous research has sought to evaluate functional independence between mands and tacts by teaching one operant and testing for the emergence of the untaught operant. Generally, four performances have been observed during posttraining tests for emergent responding: emergent dependence, directly trained dependence, modified antecedent dependence, and functional independence.

Emergent dependence refers to performances that indicated an immediate emergence of the untaught mand or tact following training in the other operant (Egan \& Barnes-Homes, 2008; Petursdottir, Carr, \& Michael, 2005; Sundberg, San Juan, Dawdy, \& Arguelles, 1990). These studies showed that functional independence between mands and tacts is not always demonstrable.

Directly trained dependence refers to performances that indicate an initial lack of untaught mand or tact emergence following training in the other operant (Hall \& Sundberg, 1987; Nuzzolo-Gomez \& Greer, 2004; Partington, Sundberg, Newhouse, \& Spengler, 1994; Sigafoos, Reichle, Doss, Hall, \& Pettitt, 1990). However, these studies subsequently demonstrated emergent responding through the use of transfer-of-stimulus-control procedures (Partington et al., 1994), exemplar training (Hall \& Sundberg, 1987; Sigafoos et al., 1990), or multiple exemplar training (Nuzzolo-Gomez \& Greer, 2004). In general, these studies showed that emergent responding was demonstrated following specific training procedures to transfer control from the trained to the untrained operant.

Modified antecedent dependence refers to the emergence of mand or tact operants that occurs under some, but not all, antecedent conditions. Two recent studies demonstrated that an initial lack of mand/tact emergence was observed following tact/mand training in standard antecedent conditions (Egan \& Barnes-Holmes, 2008, 2009). An emergence of the untrained operant was subsequently overcome under modified antecedent probe conditions in which specific vocal (Egan \& Barnes-Holmes, 2009) or specific vocal and gestural (Egan \& Barnes-Holmes, 2008) antecedent cues were present.

Functional independence refers to the absence of mand or tact emergence following training in the other operant (tact or mand). Two studies have demonstrated functional independence; however, those studies did not evaluate the 
effects of transfer-of-stimulus-control procedures (Lamarre \& Holland, 1985; Twyman, 1996). It is unclear, therefore, whether functional independence would have been maintained in the presence of minimal training procedures.

Although Skinner (1957) suggested functional independence between mand and tact operants, he also observed that the transfer of behavioral control across mands and tacts occurred readily in the mature speaker. To account for this observed transfer, Skinner described the occurrence of "impure" verbal operants. Impure verbal operants are mands and tacts that share common or mixed controlling variables. For example, a child sees a toy that he or she wants (a discriminative stimulus [SD] and motivation to receive item), responds, "Can I have the toy?," and then receives the toy (specific reinforcer). In this case, a discriminative stimulus (a toy) may have evoked the response "Can I have the toy?" This example describes a mixture of mand and tact antecedent conditions. The response specified the reinforcer and was followed by the delivery of the toy to the child. Thus, the consequent conditions defining the mand operant were presented. Skinner reasoned that tact emergence might result when the mand response was reinforced in the presence of a common nonverbal SD.

Recent research has explored a number of variables that might be responsible for the lack of emergent responding across mand/tact operants, and, in particular, antecedent stimuli seem to be important in this regard (Egan \& Barnes-Holmes, 2008, 2009). Specifically, training in one verbal operant (either mand or tact) did not result in the emergence of the other verbal operant (tact or mand) under standard antecedent conditions. However, emergent responding was demonstrated under modified antecedent conditions. Thus, functional independence was no longer maintained when modified antecedent conditions were employed. Therefore, mand and tact operant classes were not completely separate or functionally independent, despite the appearance of independence during standard antecedent probe conditions.

In undertaking further research in this area, it may be useful to note that studies on mand-tact functional independence have tended to focus on the relation between these two verbal operants without addressing the possibly important role played by the listener's repertoire. The role of the listener has been highlighted in a relatively recent behavior-analytic theory of naming (Horne \& Lowe, 1996). Furthermore, researchers interested in Relational Frame Theory (Hayes, Barnes-Holmes, \& Roche, 2001), a modern behavioral account of human language and cognition, have argued that emergent or derived listener responses may be observed in young children in the absence of productive speech (Lipkens, Hayes, \& Hayes, 1993).

Despite this recent focus on the role of the listener repertoire in emergent verbal performances, the effects of listener training on the emergence of mand/tact verbal operants have not been directly tested. Studies have shown that training a response as a listener does not readily result in the emergence of that response as a speaker (Guess \& Baer, 1973; Keller \& Bucher, 1979; Lamarre \& Holland, 1985; Wynn \& Smith, 2003), but results also indicate that there are individual differences in the effects of listener training on speaker responses (Wynn \& Smith, 2003). The current study therefore attempted to evaluate the differential effects of listener training, tact training, and a combination of listener and tact training on mand emergence. In addition, a modified antecedent condition was included to determine what role, if any, an antecedent would play in producing emergence. Mand emergence was evaluated 
using experimental procedures that partially replicated the work of Lamarre and Holland (1985); however, in the present study, three relational responses (left/right, on/under, front/back) were trained using assigned nonsense labels (tef/girt, stref/stal, and nor/cak, respectively). Nonsense labels were selected in order to eliminate the effects of a prior instructional history with the target relations the participants may have had.

\section{Method}

\section{Participants, Settings, and Materials}

The participants were eight boys, aged 7 to 11 years, classified as having autism spectrum disorders (ASD). As part of ongoing school-based language training programs, the students had received prior instruction to respond to object labels under the controlling variables of the mand and the tact.

Each participant sat at a table across from the experimenter. The training stimuli were three sets of object pairs: a fork and scissors (Set 1), a cup and sunglasses (Set 2), and a block and spoon (Set 3). Each set was used for one training phase only. The experimenter placed the items on the table in front of the participant prior to each trial, and the locations were rotated across trials in random order.

\section{Dependent Variable}

The dependent variable was the number of correct responses to probes for untaught "left/right," "on/under," or "in front/behind" relations under standard mand operant conditions (see Table 1) using the assigned nonsense label.

Table 1

Operant Components for Independent and Dependent Variables

\begin{tabular}{|c|c|c|c|c|}
\hline Condition & $\begin{array}{l}\text { Establishing } \\
\text { operation }\end{array}$ & Antecedent & Response & Consequence \\
\hline $\begin{array}{l}\text { Standard } \\
\text { mand }\end{array}$ & $\begin{array}{l}\text { Missing item } \\
\text { in target } \\
\text { location }\end{array}$ & $\begin{array}{c}\text { "Where do you } \\
\text { want me to put } \\
\text { the [object]?" }\end{array}$ & $\begin{array}{l}\text { "Location" using } \\
\text { nonsense label }\end{array}$ & $\begin{array}{l}\text { Experimenter places } \\
\text { item correctly or } \\
\text { incorrectly (1/4) and } \\
\text { asks, "Did I get it } \\
\text { correct?" }\end{array}$ \\
\hline Listener & $\mathrm{N} / \mathrm{A}$ & $\begin{array}{l}\text { "Put the [object] } \\
\text { [location]." }\end{array}$ & $\begin{array}{l}\text { Object placed } \\
\text { in location } \\
\text { specified. }\end{array}$ & Praise and tokens \\
\hline Tact & $\mathrm{N} / \mathrm{A}$ & $\begin{array}{l}\text { "Where is the } \\
\text { [object]?" }\end{array}$ & $\begin{array}{l}\text { "Location" using } \\
\text { nonsense label }\end{array}$ & Praise and tokens \\
\hline $\begin{array}{l}\text { Listener- } \\
\text { tact } \\
\text { combined }\end{array}$ & $\mathrm{N} / \mathrm{A}$ & $\begin{array}{l}\text { "Where is the } \\
\text { [object]?" or } \\
\text { "Put the [object] } \\
\text { [location]." }\end{array}$ & $\begin{array}{l}\text { "Location" or } \\
\text { object placed } \\
\text { in location } \\
\text { specified }\end{array}$ & Praise and tokens \\
\hline $\begin{array}{l}\text { Modified } \\
\text { mand }\end{array}$ & $\begin{array}{l}\text { Missing item } \\
\text { in target } \\
\text { location }\end{array}$ & $\begin{array}{c}\text { "Where do you } \\
\text { want me to put } \\
\text { the [object]? } \\
\text { Which side?" }\end{array}$ & $\begin{array}{l}\text { "Location" using } \\
\text { nonsense label }\end{array}$ & $\begin{array}{l}\text { Experimenter places } \\
\text { item correctly or } \\
\text { incorrectly (1/4) and } \\
\text { asks, "Did I get it } \\
\text { correct?" }\end{array}$ \\
\hline
\end{tabular}




\section{Independent Variable}

Two categories of independent variable were presented in the current experiment: type of experimental training and type of postexperimental probe.

Type of experimental training. Each participant was taught to respond to three sets of stimuli, each trained using a different type of training procedure. The three training procedures were listener training, tact training, and listener-tact training. The training conditions were staggered and counterbalanced across participants.

Type of postexperimental probe. Participants 1 through 6 were tested for the emergence of mands under standard (vocal) antecedent conditions following experimental training. For those participants who failed to pass standard mand probes, an additional probe for mands was conducted under modified (vocal and gestural) antecedent conditions (see Table 1). For Participants 7 and 8, the standard and modified antecedent probes were conducted throughout the pre- and postexperimental conditions in order to determine what effect, if any, the training conditions had on emergent responding during the modified antecedent conditions.

\section{Procedure}

The experimental sequence included prerequisite skills training, experimental training, and experimental probes.

Prerequisite skills training. The prerequisite skills training involved discrimination of objects employed in the study, tacts for objects employed in the study, and accuracy in the participants' evaluation of the experimenters' compliance with requests.

Discrimination of objects (listener). The experimenter placed the six objects on the table in front of the participant and instructed, "Point to the [object]." A correct response was recorded when the participant identified the corresponding item by pointing. If the participant touched more than one item or did not respond within 5 seconds of the experimenter's instruction, an incorrect response was recorded. A total of 6 probe trials were presented. Participants who scored 6/6 consecutive correct trials continued to the tact probes (described below). None of the participants made any errors during probes.

Tacts objects (speaker). The experimenter held up one item in front of the participant and asked, "What is it?" A correct response was defined as the participant's vocally identifying the item presented. A response was considered incorrect if the participant inaccurately named the item or gave no response within 5 seconds of item presentation. Each item was presented once in random order across 6 probe trials. Participants who scored 6/6 consecutive correct trials continued to the reliability probes (described below). No participants made any errors during probes.

Mand assessment training. Mand assessment training taught the participants to evaluate the accuracy of the experimenter's responding in compliance with participant instructions. The training was implemented for those participants who failed probes for accurate mand assessment. To probe for the participants' accuracy in evaluating the experimenter's performance, an identitymatching task was used. The experimenter first modelled the presentation 
of instructional trials for identity matching, including the presentation of a scripted antecedent (in the presence of 3 comparison stimuli, the experimenter held up a sample stimulus and said, "Match"), and the reinforcement or correction of correct and incorrect responses emitted by the student, respectively. The experimenter then instructed, "It's your turn to be the teacher. You pass me a picture and say 'Match.' After I match I will ask you, 'Did I get it correct or incorrect?' When I get it correct, you say 'Yes.' When I get it incorrect, you say 'No.' " The participant was required to evaluate the experimenter's performance accurately on $4 / 4$ consecutive probe trials in order to pass the mand assessment probes. Three of the eight participants failed probes for accurate mand assessment and therefore required training. To train this skill, the identitymatching task described above was used. The participant was first taught to present instructional trials to the experimenter using response prompts, such as modelling and verbal instructions. Following each response, either correct or incorrect, the experimenter asked, "Did I get it correct?" The participant was taught to respond with "yes" or "no." Training continued until the participant accurately evaluated the experimenters' responding on 8/8 consecutive trials.

Experimental training. Each participant was trained across three experimental conditions: listener training, tact training, and listener-tact training. The training conditions were introduced in a staggered fashion, and the sequence of introduction of the training conditions was counterbalanced across participants to control for any order effects. Standard mand probes were conducted following training, to test for the emergence of mands. Participants showing variability in mand emergence following initial training received experimental training a second time in order to determine the effects of further exposure to each training type (Participants 2 and 5). Participants failing standard mand probes following training were tested with modified mand probes (Participants 2, 5, and 6). The modified mand probes were introduced simultaneously for Participant 2, in a staggered fashion for Participants 5 and 6, and throughout the pre- and postexperimental sessions for Participants 7 and 8. Participants demonstrating mand emergence following only one type of experimental training received training a second time across the remaining stimulus sets to determine the effects of further exposure to the training type (Participants 3 and 7). In this case, the criterion for mand emergence was $4 / 4$ correct responses to mand probes across two consecutive probe sessions following only one training type.

Listener training. The experimenter placed an object on the table in front of the participant and held up the remaining object from the assigned set. The experimenter instructed, "Put the [object] [location]" (e.g., "Put the fork nor"). A correct response was defined as the participant placing the object in the location corresponding to the assigned nonsense label. Tokens were delivered for every three correct responses, on average, and were exchanged for access to preferred items. Incorrect responses were followed by a correction procedure, whereby the experimenter repeated the instruction and pointed to the correct location. Criterion was set at $8 / 8$ consecutive correct responses.

Tact training. The experimenter placed one object from the assigned set on the table, and then placed the other object in the target location. The experimenter then asked, "Where is the [object]?" (e.g., "Where is the cup?"). A correct response was defined as a vocal form that specified the correct location using the nonsense label (e.g., "Strif"). Tokens were delivered and exchanged as described in the Listener Training section. In response to 
incorrect responses, the experimenter repeated the instruction and modelled the correct response, which the participant was required to echo. Criterion was set at 8/8 consecutive correct responses.

Listener-tact training. The listener-tact training procedure involved training both listener and tact responses, as described above, for a novel set of relations using nonsense labels. Training trials from each condition were presented in random order, and reinforcement and correction procedures were identical to those described above. Criterion for mastery was set at $8 / 8$ consecutive correct responses, including 4 listener responses and 4 tact responses.

Upon completion of the study, participants were taught to respond accurately to left/right, in front/behind, and on/under relations in mand and tact conditions in order to replace the nonsense labels acquired during training.

Experimental probes-modified mand probes. The experimenter placed one object from the assigned set on the table and held up the remaining object. The experimenter asked, "Where do you want me to put the [object]? Which side?" while pointing to each of the target locations for each trial. Target responses were vocal forms of a target location using the nonsense label (e.g., "Tef”). Following each response, the experimenter placed the object in a location, and asked, "Did I get it correct?" The participant was required to evaluate the experimenter's response accurately. Accurate evaluations were recorded as correct responses. Inaccurate evaluations, and a failure to respond within 5 seconds, were recorded as incorrect responses. The experimenter placed the item in the wrong location once every four trials in order to test for accurate discrimination of the target location by the participants. Four probes were conducted, with two trials targeted for each location. No reinforcement or correction procedures were used during probes.

Listener and tact probes. The listener and tact probes were identical to the listener and tact training trials described above, except that there were no consequences delivered for responses. Probe sessions consisted of four probe trials.

Standard mand probes. The standard mand probe procedures were identical to modified mand probes except that the antecedent during the standard conditions was "Where do you want me to put the [object]?" The experimenter did not ask, "Which side?" or point to the target locations. Probe sessions consisted of four probe trials.

\section{Interobserver Agreement}

Thirty-three percent of training trials (162/484) and 29\% of testing trials (620/2154) were videotaped and scored by an independent observer. Interobserver agreement (IOA) was calculated by dividing the total number of agreements on the occurrence of correct and incorrect responses by the total number of agreements plus disagreements, and this ratio was converted to a percentage. Agreement was scored at 100\% for training trials and $99 \%$ for testing trials.

\section{Results}

The data for responses to experimental mand probes for each participant are presented in Figures 1 through 3. 
Participants 1 and 4 (see Figure 1) achieved criterion-level correct responses to experimental mand probes following all three training conditions. For these participants, therefore, mands emerged regardless of the type of training received. Modified mand probes were therefore not required.

Participants 2, 5, and 6 (see Figure 2) achieved variable scores (0/4-4/4) on standard mand probes following all three training conditions. Therefore, mands did not consistently emerge under standard conditions. Modified mand probes, however, showed scores of $4 / 4$ correct responses, regardless of the training condition. For these participants, therefore, the modified antecedent controlled the emergence of mands.

P1
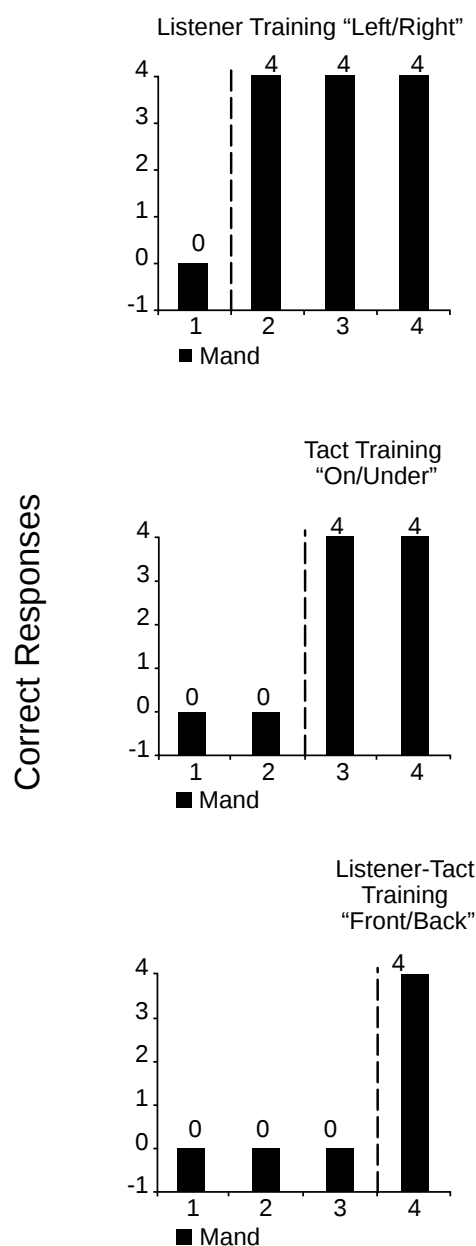

P4

Listener-Tact Training "Left/Right"

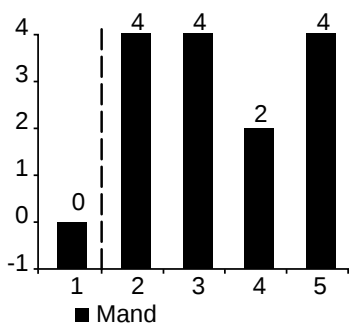

Listener Training "Front/Back"

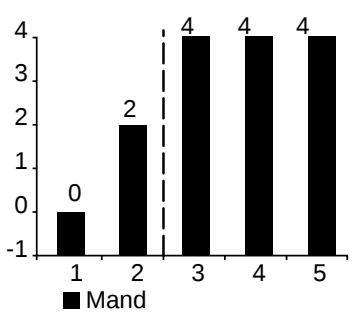

Tact Training "On/Under"

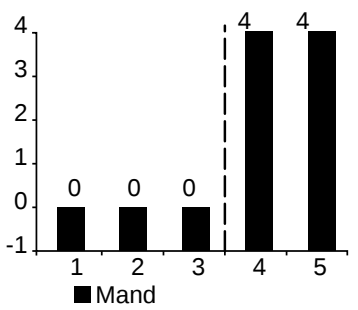

\section{Sessions}

Figure 1. Correct responses for Participants 1 and 4 during pre- and postexperimental mand probes. 
P2

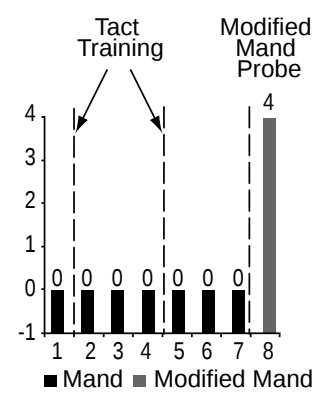

P5

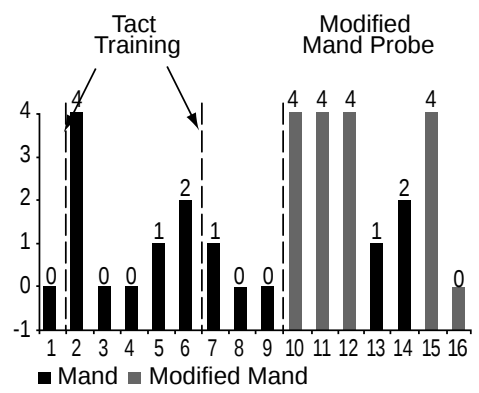

P6

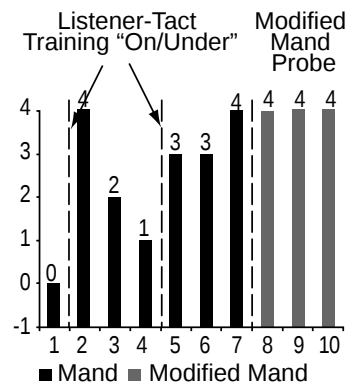

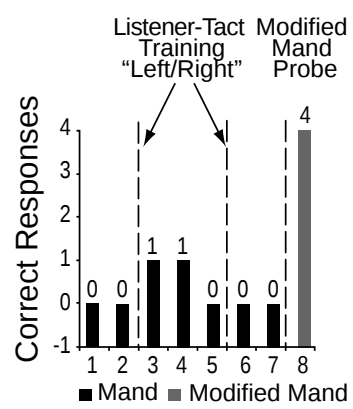

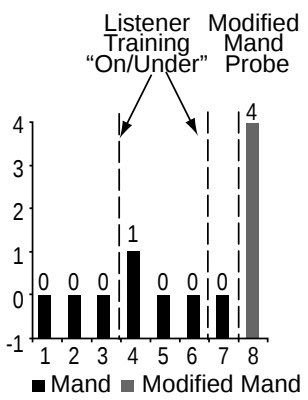

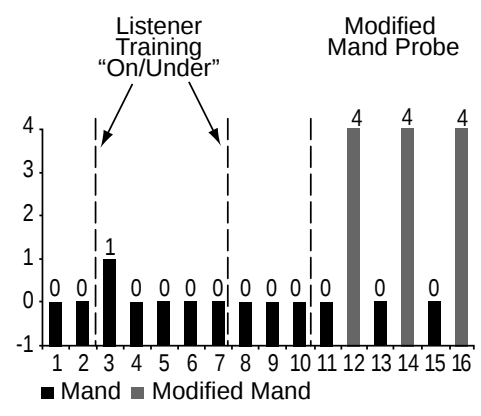

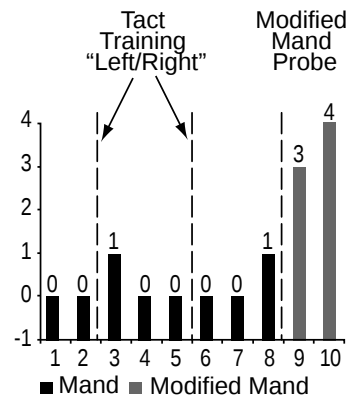

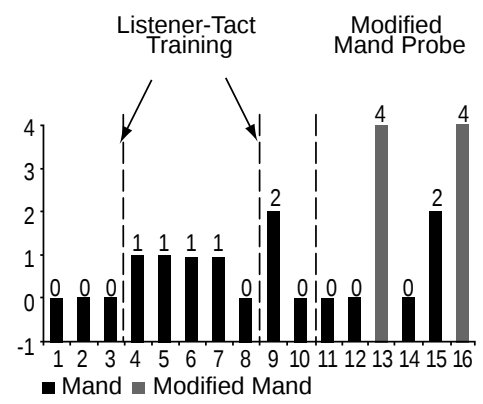

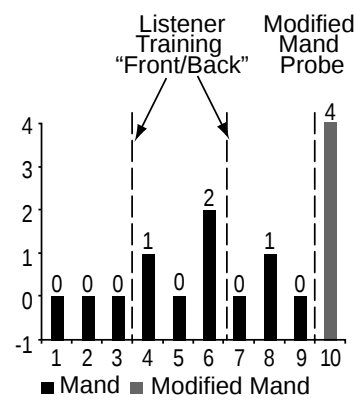

Sessions

Figure 2. Correct responses for Participants 2, 5, and 6 during pre- and postexperimental mand probes.

Participants 3, 7, and 8 (see Figure 3) achieved variable scores (0/4-4/4) on mand probes following each of the training conditions. Each of the participants demonstrated higher accuracy and/or maintenance of mand emergence under both standard and modified antecedent conditions following listener-tact training. However, the extent of emergent responding varied across participants. Participant 3 demonstrated an emergence of mands following listener-tact training; however, criterion levels of responding (4/4 across two successive sessions) were not achieved for Set 1 stimuli. Modified mand probes were not required, given that the responding occurred during standard mand conditions. For Participant 7, mand emergence was immediately observed in both standard and modified antecedent conditions following 
listener-tact training, while a delayed emergence of mands was observed following listener training. Participant 8 demonstrated some mand emergence following tact training and listener-tact training only. Unfortunately, Participant 8 was unavailable for further experimental training.

There were no consistent differences across participants in the number of training trials required to achieve criterion levels of responding across the three training types. Thus, the differences in mand emergence observed during post-training probes were not attributable to differences in the number of training trials conducted.

P3
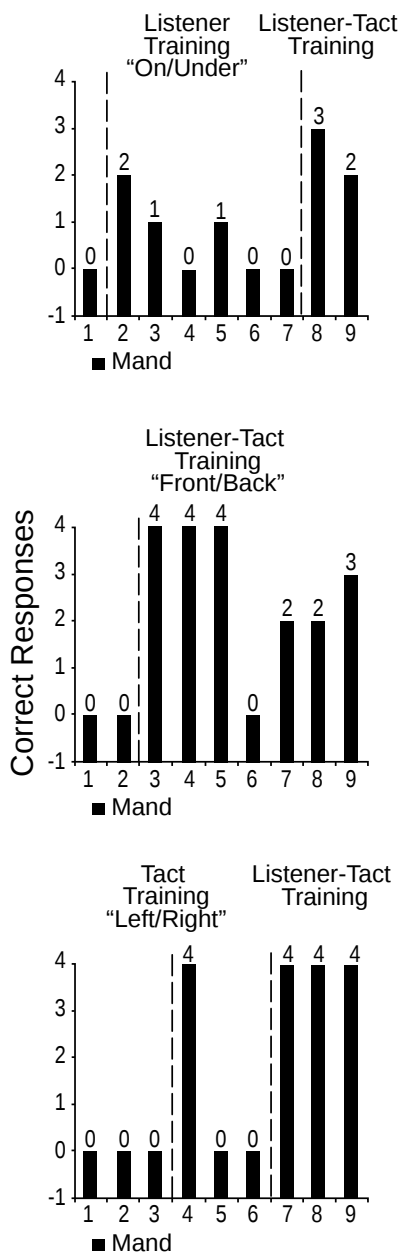

P7

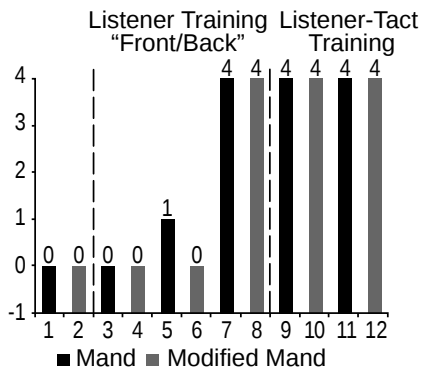

$\begin{array}{cc}\text { Tact Training } & \text { Listener-Tact } \\ \text { "On/Under" } & \text { Training }\end{array}$

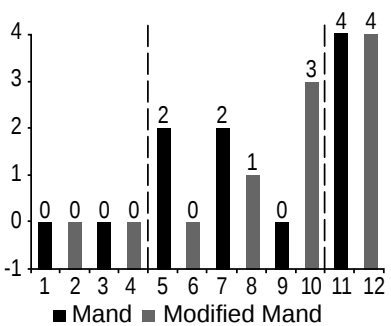

Listener-Tact

Training "Left/Right"

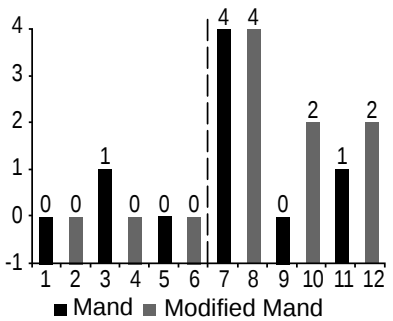

P8

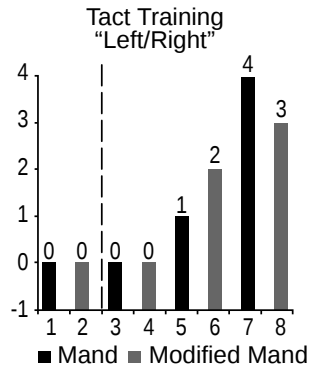

Listener-Tact Training

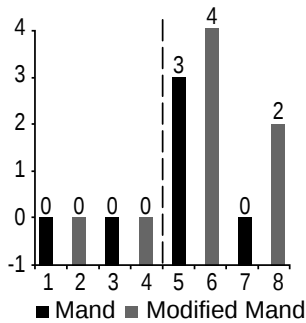

Listener

Training "On/Under"

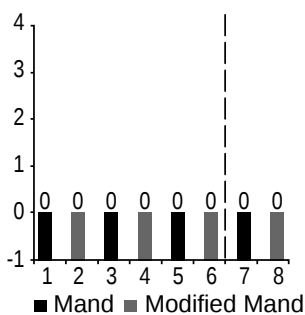

\section{Sessions}

Figure 3. Correct responses for Participant 3, 7, and 8 during pre- and postexperimental mand probes.

Following tact training, all of the participants demonstrated an emergence of listener responses during probes. However, tact responses did not reliably emerge following listener training. These data indicate a lack 
of bi-directional responding across listener and tact responses for these participants.

The participants emitted errors during mand probes that included responses such as "There" or "On that" when asked, "Where do you want me to put the [item]?" Thus, participants may have continued to respond during mand probe sessions with responses established outside the experimental conditions. Consistent with previous research, the presentation of the modified antecedent may have functioned as a verbal discriminative stimulus that cued participants to respond in the context of the experimental training (Egan \& Barnes-Holmes, 2008, 2009).

Anecdotally, the participants reliably scored the experimenter's responses as correct or incorrect during pre- and posttraining mand probes. Thus, there was some evidence of correspondence between the form of the participants' mands and the available target relational locations.

In summary, mands emerged for all 8 participants, but the conditions required to establish and/or demonstrate emergence differed across participants. Overall, three different performance types resulted and are summarized as follows. First, mand emergence was observed following all three training conditions, demonstrating no difference in the effects of the training types (Participants 1 and 4). Second, the training types had variable effects across behaviors and participants, but modified antecedent conditions consistently produced emergence where standard antecedent conditions did not (Participants 2, 5, and 6). Third, mand emergence was variably demonstrated following training; however, listener-tact training resulted in either greater accuracy or maintenance when compared with listener-only or tact-only training (Participant 3, 7, and 8). This result is consistent with the performance of Participant 6, who demonstrated consistent emergence and maintenance of mands following listener-tact training.

It is interesting that Participants 7 and 8 demonstrated an emergence of mands in the standard and modified conditions immediately following the listener-tact training. Both participants also demonstrated a delayed emergence of standard and modified mands in the listener training conditions (for Participant 7), and the tact training conditions (for Participants 7 and 8). The reason for this unexpected performance is unknown at the present time. It seems possible that the listener-tact training received for one set of responses resulted in the generalization of responding to another set that did not receive direct listener-tact training. For example, for Participant 7 , the listener-tact training was implemented for "tef/girt" responses prior to probe session 7. Measures of emergent mand responding following this training resulted in scores of $4 / 4$ across standard and modified mand probes during sessions 7 and 8 . Notably, it was during sessions 7 and 8 for responses "nor/cak" that the "spontaneous" emergence was observed. However, there are insufficient data to draw this conclusion. Future research might investigate this more systematically.

\section{General Discussion}

This study reported findings evaluating the differential effects of listener and tact training on the emergence of mands. In addition, the role of modified antecedent conditions in establishing mand emergence was examined. The results were variable and thus did not clearly demonstrate whether 
the training types had a differential effect on emergent responding during the posttraining mand probe conditions. However, results showed that modified antecedent conditions exerted control over emergent mand responding for some of the participants $(2,5$, and 6$)$. In general, two outcomes were observed: emergent dependence and modified antecedent dependence.

Overall, two participants (Participants 1 and 4) demonstrated the emergent dependence of untaught mands following all three training types. In other words, for these participants, training type did not appear to affect the emergence of posttraining mands. Furthermore, mands emerged under standard antecedent conditions, thus indicating that modified antecedent conditions were not required for posttraining mand emergence. These findings are consistent with previous research demonstrating initial emergence of mand/tact verbal operants following training in the other operant (Egan \& Barnes-Holmes, 2008; Petursdottir et al., 2005).

In contrast, three participants (Participants 2, 5, and 6) demonstrated mand emergence under modified, but not standard, antecedent conditions, regardless of the type of training received. Specifically, the initial functional independence observed in standard antecedent conditions during posttraining probes was subsequently overcome by the introduction of the modified antecedent. Notably, these findings are consistent with previous research indicating that antecedent conditions control the emergence of untrained mand or tact operants following training in the other operant (Egan \& Barnes-Holmes, 2008, 2009). The authors concluded that the modified antecedent functioned as a verbal discriminative stimulus that cued participants to respond in the context of the experimental conditions.

Finally, for three participants (Participants 3, 7, and 8) a modified antecedent dependence was observed for some relational responses, whereas emergent dependence was demonstrated for others. In other words, the same participant demonstrated emergent dependence or modified antecedent dependence across relational responses. For Participant 7, emergence was observed across all three training types; however, an emergent dependence of mands was observed following the combination of listener and tact training only. Subsequent listener-tact training for Participant 7 across all three sets of relational responses resulted in mand emergence. Thus, for this participant, listener-tact training evoked emergent mand responding when listener training and tact training alone did not produce consistent emergence. Participant 8 demonstrated an emergence of mands following listener-tact and tact training. Unfortunately Participant 8 was unavailable for follow-up training. Similarly, Participant 3 demonstrated and maintained mand emergence following listener-tact training, although some emergence was also demonstrated following tact training. These findings support previous research demonstrating that initial functional independence can be overcome following specific training procedures (Hall \& Sundberg, 1987; Nuzzolo-Gomez \& Greer, 2004; Partington et al., 1994; Sigafoos et al., 1990). Notably, unlike previous research, mand emergence was established in the present study using training procedures that did not directly train the mand response. This finding is significant because it provides preliminary evidence that specific training procedures can be used to establish emergent or generative mands without direct instruction.

In general, the results reported in the present study suggest that modified antecedent conditions are important in establishing mand emergence. 
Furthermore, these findings offer some preliminary evidence that combined listener-tact training may also be important in mand emergence. However, the small sample size, as well as the variability in performances across participants, prevents any strong conclusions from being made regarding listener-tact training and mand emergence.

Given the lack of emergent responding observed during standard mand probes, some discussion of the establishing operation is warranted. According to Skinner's (1957) definition, the primary variable controlling the mand is the presence of an establishing operation. In the present study, the experimenter withheld the placement of one item in order to establish motivation for the participant to mand for the accurate placement of the other item. The corresponding reinforcement for the mand was correct placement of the item. However, in the absence of further procedures to identify the reinforcing value of the consequence, it is not possible to evaluate the presence or strength of the EO. In other words, it is not clear that the responses emitted by participants were mands under the control of the EO and corresponding consequence. Thus, the failure to observe emergent mand responses during standard mand probe sessions may be explained, at least in part, by the presence or strength of the EOs.

Mand responses observed in the present study were evoked, at least in part, by verbal (vocal and/or gestural) antecedents and thus may be more accurately described as impure mands. However, for three participants (Participants 2, 5, and 6), modified antecedent conditions evoked emergent responding when standard antecedent conditions did not. Therefore, the form of the verbal SD determined the emergence of mands for these participants. This finding is consistent with previous research demonstrating that the form of antecedent SD presented during mand probes may control emergent responding (Egan \& Barnes-Holmes, 2008, 2009). Thus, future research should consider the form of the SD employed during emergent mand probes.

At the present time it remains unclear why the combined listener-tact training sometimes produced the emergent performances. It may be that the combined training helped to establish mutually entailed or bi-directional stimulus relations between the names and objects. In effect, during a listener trial, the participants were trained to hear-name/see object, but during a tact trial, see-object/hear-say name was reinforced. According to Relational Frame Theory (e.g., Hayes et al., 2001; Horne \& Lowe, 1996; Sidman, 1994), such bi-directional training may serve to establish a genuinely verbal or symbolic relation between the word and object. When such a relation is established, one would expect to observe, under appropriate contextual conditions, emergent performances, such as emergent manding (see, also, Barnes-Holmes, Barnes-Holmes, \& Cullinan, 2000; Horne \& Lowe, 1996). This interpretation of the listener-tact training effect warrants systematic investigation.

The present results indicated that modified antecedent conditions exerted control over the emergence of mands. It remains to be determined, however, whether the mands that emerged under modified antecedent conditions actually represent cases of initial functional independence. Specifically, if adequate antecedent control procedures had been employed throughout the study, emergent responding may have been observed.

In general, research in the wider literature has reported inconsistent support for functional independence. The findings from this study support 
previous research indicating that appropriate antecedent conditions are critical in demonstrating emergent mands (Egan \& Barnes-Holmes, 2008, 2009). In addition, some preliminary results suggest that combined listener-tact repertoires may be important for emergent mand/tact operants. However, the variability of the results reported limits the strength of the conclusions that can be drawn. Therefore, much more empirical work would be necessary to determine the extent to which these combined repertoires are important. The present study is limited by the experimental design selected. Future research should evaluate the effects of training types on mand emergence using experimental designs that allow the demonstration of functional control over the dependent and independent variables.

A major challenge facing behavior analysts working with students with autism spectrum disorders is the lack of emergent, or "generative," verbal behavior. Therefore, identifying the learning histories necessary for a child to demonstrate emergent responding across distinct verbal operants might prove useful for establishing appropriate teaching techniques. The work reported herein highlights important considerations in the demonstration of emergent mand/tact verbal operants. In addition, the work offers a preliminary study of strategies that may effectively establish emergent responding.

\section{References}

BARNES-HOMES, D., BARNES-HOMES, Y., \& CULLINAN, V. (2000). Relational frame theory and Skinner's Verbal Behavior: A possible synthesis. The Behavior Analyst, 23, 69-84.

EGAN, C. E., \& BARNES-HOLMES, D. (2008). Examining antecedent control over emergent mands and tacts in young children. Manuscript submitted for publication.

EGAN, C. E., \& BARNES-HOLMES, D. (2009). Emergence of tacts following mand training in young children with autism. Journal of Applied Behavior Analysis, 42, 691-696.

GUESS, D., \& BAER, D. M. (1973). An analysis of individual differences in generalization between receptive and productive language in retarded children. Journal of Applied Behavior Analysis, 6, 311-329.

HALL, G., \& SUNDBERG, M. L. (1987). Teaching mands by manipulating conditioned establishing operations. The Analysis of Verbal Behavior, 5, 41-53.

HAYES, S. C., BARNES-HOLMES, D., \& ROCHE, B. (Eds.). (2001). Relational frame theory: A post-Skinnerian account of human language and cognition. New York: Klewer Academic/Plenum.

HERNANDEZ, E., HANLEY, G. P., INGVARSSON, E. I., \& TIGER, J. H. (2007). A preliminary evaluation of the emergence of novel mand forms. Journal of Applied Behavior Analysis, 40, 137-156.

HORNE, P. J., \& LOWE, C. F. (1996). On the origins of naming and other symbolic behavior. Journal of the Experimental Analysis of Behavior, 65, $185-241$.

KELLER, F. M., \& BUCHER, B. D. (1979). Transfer between receptive and productive language in developmentally disabled children. Journal of Applied Behavior Analysis, 12, 311.

LAMARRRE, J., \& HOLLAND, J. (1985). The functional independence of mands and tacts. Journal of the Experimental Analysis of Behavior, 43, 5-19. 
LIPKENS, G., HAYES, S. C., \& HAYES, L. J. (1993). Longitudinal study of derived stimulus relations in an infant. Journal of Experimental Child Psychology, 56, 201-239.

MICHAEL, J. (1982). Distinguishing between discriminative and motivational functions of stimuli. Journal of the Experimental Analysis of Behavior, 37, 149-155.

NUZZOLO-GOMEZ, R., \& GREER, R. D. (2004). Emergence of untaught mands or tacts of novel adjective-object pairs as a function of instructional history. The Analysis of Verbal Behavior, 20, 63-76.

PARTINGTON, J. W., SUNDBERG, M. L., NEWHOUSE, L., \& SPENGLER, S. M. (1994). Overcoming an autistic child's failure to acquire a tact repertoire. Journal of Applied Behavior Analysis, 27, 733-734.

PETURSDOTTIR, A. I., CARR, J. E., \& MICHAEL, J. ( 2005). Emergence of mands and tacts of novel objects among preschool children. The Analysis of Verbal Behavior, 21, 59-74.

ROSALES, R., \& REHFELDT, R.A. (2007). Contriving transitive conditioned establishing operations to establish derived manding skills in adults with severe developmental disabilities. Journal of Applied Behavior Analysis, 40, 105-121.

SIDMAN, M. (1994). Stimulus equivalence: A research story. Boston: Authors Cooperative.

SIGAFOOS, J., REICHLE, J., DOSS, S., HALL, K., \& PETTITT, L. (1990). “Spontaneous” transfer of stimulus control from tact to mand contingencies. Research in Developmental Disabilities, 11, 165-176.

SKINNER, B. F. (1957). Verbal behavior. New York: Appleton-Century-Crofts.

SUNDBERG, M. L., \& PARTINGTON, J. W. (1998). Teaching language to children with autism or other developmental disabilities. Danville, CA: Behavior Analysts.

SUNDBERG, M. L., SAN JUAN, B., DAWDY, M., \& ARGUELLES, M. (1990). The acquisition of tacts, mands, and intraverbals by individuals with traumatic brain injury. The Analysis of Verbal Behavior, 8, 83-99.

TWYMAN, J. (1996). The functional independence of impure mands and tacts of abstract stimulus properties. The Analysis of Verbal Behavior, 13, $1-19$.

WYNN, J. W., \& SMITH, T. (2003). Generalization between receptive and expressive language in young children with autism. Behavioral Interventions, 18, 245-266. 


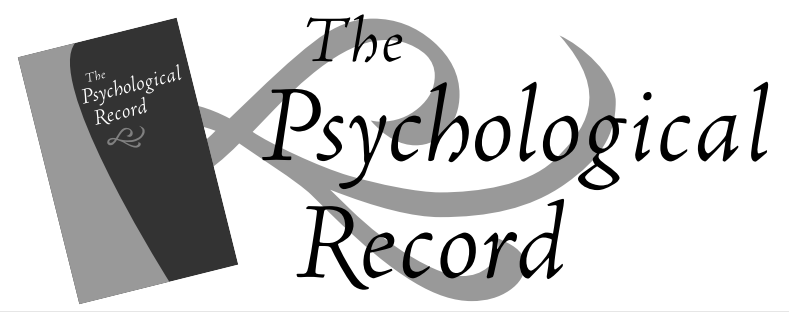

The Psychological Record (ISSN 0033-2933) is a nonprofit journal of psychology appearing quarterly. Subscriptions are available on a calendar year basis (January through December) and it is published by Southern Illinois University Carbondale. The Psychological Record is primarily for the publication of experimental or theoretical papers in many areas of psychology. The journal was founded by renowned interbehaviorist J.R. Kantor, with one of the most influential American psychologists, B.F. Skinner, serving as the experimental department editor at the journal's inception.

\section{DOES YOUR LIBRARY SUBSCRIBE TO THE PSYCHOLOGICAL RECORD?}

IF NOT, THEN COPY THIS FORM FOR YOUR REFERENCE LIBRARIAN.

To be filled out by employee or faculty member

I would like to request that our library purchase a 2010 subscription to

The Psychological Record (ISSN 0033-2933)

Name

Department

Signature

To be filled out by the reference librariran

The Psychological Record (ISSN 0033-2933) Volume 60 (2010):

\$160 (USA) \$170 (International)

Institution Name

Address

City State Zip Country

Payment: $\square$ Check (in US currency) made payable to: The Psychological Record

$\square$ VISA $\square$ MasterCard Credit Card \#:

Expires:

Mail to:

The Psychological Record

Security Code

Rehabilitation Institute

Rehn Hall - Mail Code 4609

Signature:

Southern Illinois University Carbondale

1025 Lincoln Drive

Carbondale IL 62901 